\title{
PENGEMBANGAN BLOG SEBAGAI BAHAN AJAR PENGOLAHAN DAN PENYAJIAN MAKANAN KONTINENTAL UNTUK MENINGKATKAN HASIL BELAJAR SISWA SMK PROGRAM STUDI TATA BOGA
}

\author{
Uut Susiyanti \\ SMK Ibu Kartini, Semarang, Indonesia. \\ ute.brownies.cute@gmail.com
}

Disetujui: Maret 2018. Dipublikasikan: April 2018

\begin{abstract}
ABSTRAK
Penelitian ini bertujuan untuk mengembangkan blog sebagai bahan ajar Pengolahan dan Penyajian Makanan Kontinental untuk meningkatkan hasil belajar siswa SMK program studi Tata Boga, menguji kelayakan blog sebagai bahan ajar Pengolahan dan Penyajian Makanan Kontinental, menguji efektifitas penggunaan blog sebagai bahan ajar Pengolahan dan Penyajian Makanan Kontinental, menganalisis kepraktisan blog sebagai bahan ajar Pengolahan dan Penyajian Makanan Kontinental. Metode penelitian yang digunakan adalah penelitian pengembangan atau Research and Development. Tahapan dalam proses penelitian ini adalah tahap (1) studi pendahuluan; (2) perencanaan pengembangan dan validasi; (3) uji coba produk; (4) menetapkan produk final. Pengujian yang dilakukan berupa validasi oleh expert judgment atau ahli media dan materi. Metode yang digunakan dalam pengumpulan data adalah observasi dan angket kemudian data yang diperoleh di analisis dengan teknik analisis diskriptif dan uji t. Hasil uji coba siswa pada pretest mendapatkan nilai $\mathrm{t}$ hitung 0,911 dan $\mathrm{t}$ tabel 1,670 sedangkan hasil posttest menghasilkan nilai $\mathrm{t}$ hitung 3,314 dan $\mathrm{t}$ tabel 2,0 sehingga hipotesis yang dapat diambil adalah Ho ditolak jika $\mathrm{t}$ hitung $>\mathrm{t}$ tabel : bahwa terjadi peningkatan hasil belajar siswa setelah menggunakan blog sebagai bahan ajar Pengolahan dan Penyajian Makanan Kontinental dengan demikian blog efektif. Kesimpulan yang dapat diambil yaitu blog yang dikembangkan berisi materi Pengolahan dan Penyajian Makanan Kontinental yang dilengkapi dengan video dan gambar serta berisi template seperti home, profil Tata Boga, evaluasi, dan menu lain-lain. Berdasarkan uji kelayakan, blog dinyatakan layak sebagai bahan ajar Pengolahan dan Penyajian Makanan Kontinental untuk siswa SMK Tata Boga dan teruji efektif. Sedangkan hasil dari analisa kepraktisan mendapatkan respon yang baik dari siswa dan sangat baik dari guru.
\end{abstract}

Kata Kunci: Pengembangan Blog, Bahan Ajar Pengolahan dan Penyajian Makanan Kontinental, Hasil Belajar.

\section{ABSTRACT}

This study aimed to develop blog as an instructional material in processing and presenting the continental food to improve students' achievement at the culinary program of Vocational High School, analyse the feasibility of the blog as an instructional material in processing and presenting the continental food, examine the effectiveness of using blog as an instructional material in processing and presenting the continental food, analyse the practicality of the blog as an instructional material in processing and presenting the continental food. The method that was used in this study was a development research, known as the Research and Development Method. The process stages of this study were (1) a preliminary study; (2) planning the development and validation; (3) testing of products; (4) setting the final product. In examining the validity of the test, the writer used expert judgement and materials. In collecting the data, the writer used observation and questionnaire. Then, the data were analysed by descriptive analysis technique and t-test analysis. The $t$ value in the pre-test was 0,911 and $t$ table was 1,670 . While the $t$ value in the post-test was 3,314 and $t$ table was 2 . The null hypothesis or Ho is rejected if $t$ value $>t$ table: that there is significant development on the students achievement who used blogs as the instructional materials for Processing and Presenting the Continental Food. Thus, this blog is effective.It can be concluded that the blog which is developed contains the materials about processing and presenting the continental food completed by the 
videos, pictures, and template such as home, profile of culinary program, evaluation, and other menus. According to the feasibility test, this blog is said to be feasible as an instructional material in processing and presenting the continental food at the culinary program of Vocational High School students. In addition, the result of practicality analysis shows the great responses from the students and the teacher.

Keyword: Development Blog, Instructional Materials in Prpcessing and Presenting Continental Food, Learning Outcomes.

\section{PENDAHULUAN}

Perkembangan teknologi infomasi dan komunikasi (TIK) yang sangat pesat seperti komputer, perangkat lunak, kamera digital, akses internet, smartphone sangat berpengaruh terhadap pola hidup masyarakat pada umumnya, dan tehadap siswa pada khususnya. Pengaruh perkembangan TIK juga berimbas dalam dunia pendidikan, misalnya pada alat bantu mengajar seperti power point, e-book, dan proyektor yang memiliki peran besar bagi guru untuk mempermudah dalam menyampaikan materi kepada siswa, siswa dapat lebih mudah memahami materi dan konsep yang disampaikan guru. Pembelajaran dengan teknologi informasi yang dapat diterapkan dalam dunia pendidikan salah satunya adalah blog. Penggunaan blog sebagai bahan ajar non cetak menjawab tuntutan dari kurikulum 2013 yaitu adanya perubahan pola pembelajaran yang berpusat pada guru (teacher centered) menjadi pembelajaran berpusat pada siswa (student centered). Keuntungan menggunakan blog sebagai bahan ajar bagi guru adalah guru dapat mengelola kelas jika berhalangan hadir dengan memberikan tugas melalui blog, dapat melakukan diskusi tanpa melalui tatap muka, dapat menyajikan video atau gambar, dapat menjalin komunikasi antara guru dan siswa maupun siswa dengan siswa tanpa dibatasi ruang waktu, dan dapat berbagi informasi antar individu dalam satuan pendidikan maupun diluar satuan pendidikan yang sudah menjadi anggota dalam blog.
Proses pembelajaran Pengolahan dan Penyajian Makanan Kontinental masih menggunakan metode ceramah dengan dibantu media power point dan handout, yang membuat siswa merasa bosan karena konten dalam media power point terbatas pada poinpoin pokok bahasan sedangkan handout hanya berisi teks, gambar, dan tabel. Hal ini membuat siswa jenuh yang berdampak pada pencapaian hasil belajarnya dibawah KKM (Kriteria Ketuntasan Minimal). Melihat hal ini, perlu di sikapi agar siswa memiliki motivasi dalam belajar guna mencapai hasil belajar yang sudah ditentukan. Penggunaan blog sebagai bahan ajar ini diharapkan dapat memenuhi kebutuhan siswa jika menemui kesulitan dalam memahami materi Pengolahan dan Penyajian Makanan Kontinental.

Pemanfaatan blog ini diharapkan dapat membuat siswa untuk belajar dimanapun dan mampu memberikan motivasi belajar yang lebih tinggi sehingga hasil belajar siswa Tata Boga dalam mata pelajaran Pengolahan dan Penyajian Makanan Kontinental dapat meningkat.

\section{METODE PENELITIAN}

Penelitian ini menggunakan jenis penelitian Research and Development (R\&D). Research and Development yaitu metode penelitian yang digunakan untuk menghasilkan produk tertentu dan menguji dan mengkaji keefektifan produk tersebut (Sugiyono, 2010: 407). Teknik pengumpulan data dalam penelitian ini menggunakan triangulasi. Dalam teknik pengumpulan data, triangulasi 
diartikan sebagai teknik pengumpulan data yang bersifat menggabungkan dari berbagai teknik pengumpulan data dan sumber data yang telah ada (Sugiyono, 2010: 241).

Pengumpulan data menggunakan instrumen penelitian, analisis data bersifat kuantitatif/statistik dengan tujuan untuk menguji hipotesis yang telah ditetapkan. Teknik analisis data yang digunakan adalah; uji kelayakan, uji efektifitas, dan uji kepraktisan.

\section{HASIL DAN PEMBAHASAN}

\section{Uji Kelayakan Media dan Materi}

Uji kelayakan media diperoleh dari hasil validasi ahli media dan uji kelayakan materi diperoleh dari validasi ahli materi. Hasil validasi media diperoleh angka 79,50 dengan kriteria layak, sehingga blog layak atau dapat digunakan sebagai bahan ajar. Kelayakan materi diperoleh hasil 78,65 dengan kriteria layak, sehingga materi yang akan disampaikan kepada siswa dinyatakan layak atau dapat digunakan sebagai bahan ajar.

\section{Uji Efektifitas}

\section{a. Uji Normalitas}

Pengujian normalitas menggunakan

rumus Chi kuadrat dengan kriteria pengujianya adalah jika nilai $\mathrm{x} 2$ hitung lebih kecil daripada x2 tabel maka data yang diperoleh berdistribusi normal. Hasil yang diperoleh menunjukkan bahwa populasi pada kelompok kontrol dan kelompok eksperimen memiliki tingkan kecakapan yang sama.

\section{b. Uji Homogenitas}

Uji kesamaan varians menggunakan uji F, yaitu dengan menguji kesamaan beberapa varians. Hasil analisis uji kesamaan dua varians untuk pre-test maupun post-test kelas kontrol dan eksperimen menunjukkan Fhitung lebih kecil dari Ftabel (Fhitung < Ftabel), maka dapat disimpulkan bahwa kelompok kontrol dan kelompok eksperimen memiliki varians yang sama.

$$
\text { c. Uji-T }
$$

Hipotesis dari pengambilan data adalah Ho diterima jika <t1 - $\alpha$ (kedua kelompok memiliki hasil belajar yang sama) dan Ho ditolak jika >t $1-\alpha$ (kedua kelompok memiliki hasil belajar yang tidak sama) dengan taraf signifikansi $\alpha=0,05$ atau 0,05. Hasil nilai posttest menunjukkan hipotesis nol (Ho) ditolak dan hipotesis alternatif (Ha) diterima maka dinyatakan "ada perbedaan hasil belajar siswa setelah menggunakan blog sebagai bahan ajar Pengolahan dan Penyajian Makanan Kontinental". diterima dengan signifikan.

\section{d. Uji Gain}

Analisa dari hasil pre-test dan posttest menunjukkan adanya gain sebesar 0,54 pada kelompok eksperimen dengan kriteria sedang dan gain sebesar 0,44 pada kelompok kontrol dengan kriteria sedang.

\section{Uji Kepraktisan}

a. Respon Siswa dan Guru

Respon siswa terhadap blog sebagai bahan ajar Pengolahan dan Penyajian Makanan Kontinental memiliki persentase 77,08 dengan kriteria baik, sehingga pengembangan blog sebagai bahan ajar Pengolahan dan Penyajian Makanan Kontinental direspon baik oleh siswa kelas XI Tata Boga SMK Ibu Kartini Semarang.

Respon guru terhadap blog pembelajaran Pengolahan dan Penyajian Makanan Kontinenal memiliki persentase 85 dengan kriteria sangat baik, sehingga pengembangan blog sebagai bahan ajar Pengolahan dan Penyajian Makanan Kontinental diterima baik oleh guru pengampu dan dapat digunakan sebagai bahan ajar Pengolahan dan Penyajian Makanan Kontinental.

Hasil dari respon guru dan siswa terhadap penggunaan blog bahan ajar di kelas adalah bagus sekali. Terjadi peningkatan minat dan pemahaman siswa dalam mencapai hasil belajarnya. Hal ini disebabkan siswa merasa belajar dengan sesuatu yang baru, lebih interaktif, komunikatif, serta merasa 
senang karena dapat mengoperasikan pembelajaran berbasis blog secara mandiri dan mudah digunakan.

Sifat interaktivitas dan penemuan dalam pembelajaran multimedia dapat memberikan manfaat bagi pembelajaran yang pasif. Pembelajaran menggunakan blog mendukung strategi pembelajaran tipe student center, dimana siswa bertanggung jawab dalam proses belajar mereka sendiri dan siswa diharapkan mampu dalam mengoperasikan blog pembelajaran secara mandiri dengan menggunakan bantuan perangkat komputer, laptop, atau smartphone.

\section{Bentuk Pengembangan Blog sebagai Bahan Ajar Pengolahan dan Penyajian Makanan Kontinental}

Blog merupakan layanan aplikasi dari internet dengan pembuatan yang gratis dan penggunaan yang mudah sehingga blog bisa digunakan sebagai salah satu alternatif media pembelajaran. Blog dipilih sebagai media pembelajaran karena blog memiliki kelebihan-kelebihan seperti blog tidak memerlukan software khusus karena sudah tersedia dalam layanan internet; dapat digunakan untuk menampilkan teks, gambar, maupun video; dapat dilakukan pembaharuan secara berkala, mudah penggunaannya, dapat digunakan dimanapun, serta salah satu hasil dari perkembangan Teknologi dan Informasi yang belum banyak dimanfaatkan sebagai media pembelajaran.

Umumnya blog digunakan sebagai sarana menulis (curhat) dari pemilik blog, sehingga pemanfaatannya secara maksimal sebagai media pembelajaran belum banyak dilakukan. Blog yang dimiliki guru pengampu belum dimanfaatkan sebagai media pembelajaran, hal ini mendorong perlu dilakukannya pengembangan sebagai media pembelajaran Pengolahan dan Penyajian Makanan Kontinental.

Kelebihan-kelebihan blog diatas didukung oleh hasil penelitian dari Joshi and
Chugh, 2009 (dalam Mahendra) yang menuliskan bahwa blog menjadi popular karena relatif murah, mudah untuk dikembangkan, mudah digunakan, dapat digunakan untuk memberikan pekerjaan rumah siswa yang mana setiap siswa secara mandiri akan mengerjakan tugasnya masingmasing, blog memungkinkan pengguna untuk mempublikasikan (posting) yang diurutkan atas kronologis terbalik (posting terbaru berada paling atas), penugasan dapat dialokasikan oleh pendidik atau dinegosiasikan dalam kelompok, dapat ditambahkan teks, gambar grafis, link informasi dengan situs yang relevan dan data lainnya, dapat dilakukan proses editing pada post setiap saat dan memungkinkan pembaca untuk meninggalkan komentar untuk posting asli dan saling berkomentar satu sama lain.

Penggunaan blog untuk pembelajaran dapat berfungsi sebagai pengarah dalam pengembangan dan pencapaian kompetensi profesional di kalangan siswa sehingga akan menjadikan sarana yang kuat untuk meningkatkan pembelajaran siswa dan dengan di iringi dengan umpan balik dari staf pengajar guna meningkatkan kemampuan self-assessment siswa dan meta-kognitif (Pinya dan Rossello, 2014).

Pemanfaatan Teknologi Informasi dan Komunikasi yang berbasis komputer dan internet dalam bidang pendidikan ini berupa pengembangan blog yang digunakan sebagai media pembelajaran di Sekolah Menengah Kejuruan program studi Tata Boga. Weblog menurut Kindarto (2006: 1-2) merupakan teks dokumen, gambar, obyek media, dan data yang tersusun secara hierarkis dan menurut kronologi tertentu, yang dapat melalui browser internet (misalnya internet explorer), selain itu juga dikatakan bahwa blog pada dasarnya adalah jurnal yang disediakan pada web yang dapat di-update setiap hari dengan suatu aplikasi yang disediakan oleh penyedia, tidak dibutuhkan 
suatu keahlian khusus untuk melakukan update atau mengelola blog.

Pengembangan blog untuk mata pelajaran Pengolahan dan Penyajian Makanan Kontinental didasarkan pada latar belakang yang ditemui selama melakukan pengamatan proses pembelajaran di kelas. Dari hasil pengamatan tersebut diperoleh bahwa media yang digunakan oleh guru pengampu belum mampu menarik perhatian siswa selama proses pembelajaran berlangsung sehingga motivasi siswa dalam belajar rendah. Disinilah perlu dilakukannya upaya untuk menjawab permasalahan yang dihadapi siswa.

Pengembangan blog ini meliputi dari tampilan/layout dan menu-menu dalam blog yang berisi tentang Pengolahan dan Penyajian Makanan Kontinental. Selain memiliki kelebihan-kelebihan, blog juga sebagai salah satu bentuk pembelajaran Elearning dan sebagai wujud mengintegrasikan teknologi ke dalam pembelajaran di sekolah kejuruan (Hamalainen dan Cattaneo, 2015) serta menjawab perubahan metode pembelajaran dari teacher centered menjadi student centered guna menciptakan siswa yang memiliki inovasi, kreatifitas dan motivasi yang tinggi.

Layout ini dibuat dengan pengoperasian yang mudah untuk dipahami dan dioperasikan serta pemilihan background yang disesuaikan dengan tema materi pelajaran sehingga menarik. Sedangkan isi dari blog ini adalah home, profil Tata Boga, materi pelajaran, evaluasi, dan informasi sekolah tinggi lanjutan yang terdapat dalam menu lain-lain. Pada profil Tata Boga berisi tentang kompetensi, silabus, dan RPP ditujukan agar siswa paham tentang kompetensi-kompetensi apa saja yang harus dicapai nantinya setelah selesai belajar Pengolahan dan Penyajian Makanan Kontinental, silabus dan RPP siswa dapat mengetahui pokok bahasan apa saja yang akan dipelajari. Materi Pengolahan dan
Penyajian Makanan Kontinental setiap pokok bahasan akan disertai gambar maupun video untuk membantu memperjelas pemahaman siswa terhadap materi yang akan dipelajari dan dapat dilihat secara berulang saat siswa lupa atau belum jelas. Evaluasi berisi tentang latihan soal atau tugas yang dapat digunakan oleh guru ketika berhalangan hadir pada saat proses pembelajaran sehingga siswa dapat dikontrol dan dkondisikan, job sheet digunakan untuk melakukan pembelajaran praktik yang didalamnya memuat resep, cara pembuatan, rencana belanja, dan rencana alat yang harus dikerjakan siswa sebelum praktik. Validitas Blog sebagai Bahan Ajar Pengolahan dan Penyajian Makanan Kontinental

Hasil yang di diperoleh dari penilaian ahli media terhadap pengembangan blog sebagai media pembelajaran Pengolahan dan Penyajian Makanan Kontinental menerangkan bahwa blog yang dikembangkan sebagai media layak untuk digunakan. Sedangkan hasil uji kelayakan ahli materi menerangkan bahwa layak untuk digunakan sebagai media pembelajaran. Dengan perolehan hasil yang layak dari ahli media dan ahli materi maka pengembangan blog sebagai media pembelajaran Pengolahan dan Penyajian Makanan Kontinental dapat digunakan sebagai media pembelajaran. Blog sebagai media pembelajaran Pengolahan dan Penyajian Makanan Kontinental ini dikatakan layak karena di dalam blog ini memuat prinsipprinsip pemilihan media yaitu adanya tujuan yang akan dicapai, adanya peningkatan efektifitas belajar siswa, biaya pembuatan media yang tidak mahal, sesuai dengan metode pembelajaran (Rumampuk, 1988: 19).

Keefektifan Blog sebagai Bahan Ajar Pengolahan dan Penyajian Makanan 


\section{Kontinental untuk Meningkatkan Hasil Belajar Siswa}

Berdasarkan hasil uji gain diperoleh adanya peningkatan hasil belajar sesudah menggunakan blog sebagai bahan ajar Pengolahan dan Penyajian Makanan Kontinental dengan kriteria sedang. Kriteria sedang ini diperoleh karena siswa masih perlu adaptasi dengan proses pembelajaran elearning dan perubahan metode pembelajaran yang awalnya teacher centered menjadi student centered. Namun dari hasil uji gain itu menunjukkan adanya peningkatan hasil belajar dalam melakukan proses belajar mandiri (self directed learning). Blog sebagai media pembelajaran yang diisi dengan bahan ajar berfungsi sebagai perantara dalam proses pembelajaran sehingga dapat memperlancar dan meningkatkan hasil belajar siswa. Sesuai dengan definisi media pembelajaran yang dikemukakan oleh Hamalik (1990: 65) bahwa media pembelajaran adalah alat, metode dan teknik yang digunakan dalam rangka lebih mengefektifkan komunikasi dan interaksi antara guru dan siswa dalam proses pembelajaran. Hal ini berarti bahwa blog memiliki kemampuan untuk memudahkan dalam penyampaian informasi yang lebih menarik dan di rancang untuk meningkatkan kemampuan belajar mandiri (self directed learning) siswa SMK program studi Tata Boga, karena di dalam blog Makanan Kontinental mencakup persyaratan kompetensi yang harus dimiliki siswa setelah melalui pembelajaran Pengolahan dan Penyajian Makanan Kontinental, yaitu adanya resep dan cara pembuatan yang dilengkapi dengan video. Video yang diberikan dalam satu jenis pengolahan ada dua buah dengan sumber yang berbeda, agar siswa memiliki kemampuan dalam menalar dan membandingkan antara kedua video sehingga dapat diterapkan untuk menalar dalam ranah konkret (pada saat praktik) dan ranah abstrak (pada saat pembelajaran) sehingga siswa dapat melakukan proses belajar menganalisa secara mandiri dan dapat berpikir lebih kreatif dan efektif.

Hal tersebut didukung juga oleh beberapa pendapat tentang blog dalam nilai pendidikan sebagai media atau alat pembelajaran di antaranya: Tulisan Luehmann (2009) yang menjelaskan bahwa blog yang digunakan dalam pembelajaran di kelas dapat memberikan masukan, pengakuan dan kebanggan bagi siswa, hal ini dapat memberikan peningkatan motivasi siswa untuk menghasilkan kualitas belajar mereka. Sedangkan Pinya (2014) menuliskan bahwa blog dapat memberikan informasi kepada siswa tentang pembelajaran dengan bentuk dan format baru serta menjadi alat yang menawarkan kesempatan belajar yang unik.

\section{PENUTUP}

Berdasarkan pada hasil penelitian dan pembahasan, maka dapat di simpulkan sebagai berikut: (1) Blog sebagai bahan ajar, yang dikembangkan adalah fasilitas yang ada dalam website (blogspot atau blogger). Isi yang dikembangkan meliputi materi pembelajaran Pengolahan dan Penyajian Makanan Kontinental yang di upload ke dalam blog dengan template atau layout yang menarik. Template dalam blog meliputi menu home, menu profil tata boga, menu materi (dilengkapi video dan gambar), menu evaluasi, dan menu lain-lain (menampilkan infomasi pendidikan lanjutan). (2) Kelayakan blog yang dikembangkan sebagai bahan ajar Pengolahan dan Penyajian Makanan Kontinental dinyatakan layak oleh ahli media dan ahli materi. (3) Blog yang dikembangkan sebagai bahan ajar Pengolahan dan Penyajian Makanan Kontinental terbukti efektif . (4) 
Kepraktisan blog sebagai bahan ajar Pengolahan dan Penyajian Makanan Kontinental mendapatkan respon yang baik, karena siswa mendapatkan kemudahan

\section{DAFTAR PUSTAKA}

Hamalik, Oemar. 2009. Kurikulum dan Pembelajaran. Jakarta: Bumi Aksara.

Hämäläinen, R and Cattaneo, A. 2015. New TEL Environments for Vocational Education - Teacher's Instructional Perspective. Diperoleh dari Journal Vocations and LearningStudies in Vocational and Professional Education (C) Springer Science+Business Media Dordrecht 2015 10.1007/s12186-015-9128-1 (diunduh 25 April 2015).

Kindarto, Asdani. 2006. Tip Mudah Membuat Blog Bergaya dan Interaktif. Yogyakarta: Andi Offset.

Luehmann, A.L and Frink, J. 2009. How Can Blogging Help Teachers Realize the Goals of Reform-based Science Instruction? A Study of Nine Classroom Blogs. Diperoleh dari Journal of Science Education and Technology () Springer Science+Business Media, LLC 2009 10.1007/s10956-009-9150-x (diunduh 25 April 2015). dalam belajar secara berulang dimanapun dan kapanpun sehingga lebih fleksibel dan menyenangkan karena dapat diakses menggunakan smartphone.

Mahendra, I Gede Jaka. Pengembangan Media Pembelajaran Berbasis Blog Pada Mata Pelajaran Teknologi Informasi Dan Komunikasi Kelas VII SMP Negeri I Sukasada". Thesis.

Pinya, C,. dan Rosselló, M.R. 2014. "Using blogs to be aware of the development and adoption of professional skills". Education and Information Technologies The Official Journal of the IFIP Technical Committee on Education. Diperoleh dari Springer Science+Business Media New York 2014 10.1007/s10639-014-9367-z. (diunduh 25 April 2015).

Rumampuk, D.Borman. 1988. Media Instruksional IPS. Jakarta: Departemen Pendidikan dan Kebudayaan.

Sugiyono. 2010. Metode Penelitian Penelitian; Pendekatan Kuantitatif, Kualitatif, dan R\&D. Bandung: Penerbit Alfabeta. 